\title{
THE BIPOLAR SPECTRUM: DO WE NEED A SINGLE ALGORITHM FOR AFFECTIVE DISORDERS?
}

\author{
Mark Agius $^{1,2}$, Richard Bugler ${ }^{3}$, Giuseppe Tavormina ${ }^{4}$ \& Rashid Zaman ${ }^{1,2}$ \\ ${ }^{1}$ Department of Psychiatry, University of Cambridge, UK \\ ${ }^{2}$ South Essex Partnership,University Foundation Trust, UK \\ ${ }^{3}$ Clinical School, University of Cambridge, UK \\ ${ }^{4}$ Centre for Psychiatric Studies Provaglio d'Iseo Italy, Italy
}

Key words: bipolar disorder - unipolar depression - diagnosis - treatment - guidelines - suicidality

Increasing understanding of the bipolar spectrum of disorders has led to an increasing integration of concepts regarding the aetiology and treatment of affective disorders.

Thus, for example, we now understand that an illness, previously believed to be recurrent depressive disorder, may develop over time into a bipolar illness, and bipolar II illnesses may develop into bipolar I (Akiskal et al. 1995, Akiskal et al. 1996, Angst et al. 2000, Angst 2007, Benazzi et al. 2006, Benazzi et al. 2006).

It has also been suggested that there may be a continuum between Bipolar Disorder and the mood lability of Borderline Personality disorder (Benazzi et al. 2004, Benazzi et al. 2005).

Agitated depression may in fact be a mixed affective state, and injudicious use of powerful antidepressants in patients with undiagnosed bipolar disorder may lead to the development of mixed states or rapid cycling illness, as well as a complete switch from depression to mania (Akiskal et al. 2005).

Mixed states and rapid cycling states are linked with increased suicidality (Akiskal et al. 2005).

Meanwhile bipolar disorder, especially bipolar II disorder, remains a condition which is underdiagnosed and often inappropriately treated (Morselli et al. 2002, Tavormina et al. 2007, Tavormina et al. 2007, Tavormina et al. 2007). There is evidence that many patients with bipolar illness have a long duration of untreated illness analogous with the Duration of Untreated Psychosis in other psychotic illnesses (Morselli et al. 2002, Agius et al. 2007, Agius et al. 2007).

In recent years, there have also been concerns about whether general practitioners do effectively diagnose and effectively treat unipolar depression (Donaghue et al. 1996).

Unfortunately, NICE guidelines are separate for Unipolar Depression and Bipolar Illness; those for Unipolar illness advocate a 'stepped care' model, centred round primary care, while bipolar guidelines warn against injudicious use of antidepressants and the use of mood stabilisers to prevent 'switching'to mania (NICE 2004, NICE 2006).

Primary care physicians are not warned to take a full longitudinal history in depressed patients, to identify bipolar illness, nor are they trained to use mood stabilisers in patients with bipolar II disorder, and in the risks of injudicious use of antidepressants.

In practice, early Bipolar disorder will be identified and treated if Primary Care Doctors are effective in identifying and treating early cases of depression or bipolar disorder which present to them (Paykel et al. 1992). We would suggest that care should be taken that, each patient who presents with major depression, both in primary and secondary care is asked to identify any period of elated mood which they have experienced, even if this has lasted for only a few days. A family history of bipolar illness or suicide, previous episodes of hypomania, at least three recurrent depressive episodes, cyclothymia, and a seasonal onset [winter in bipolar II and summer in bipolar I patients], and migraine have all been identified as indicators of the possibility of bipolar illness. (Akiskal et al. 2005). Identifying these markers will enable patients with bipolar illness to be identified, perhaps earlier than they otherwise would (Akiskal 2006a, Akiskal 2006b, Akiskal et al. 2006c, Akiskal et al. 2006d).

The cautions that antidepressant monotherapy for bipolar disorder may precipitate hypomanic or mixed states, which are strongly associated with self harm and completed suicide, (Rihmer et al. 2006a, Rihmer et al. 2006b). and that Venlafaxine seems more likely than other antidepressants to precipitate a switch to mania in bipolar depression should then lead to a policy that, once bipolar depression is identified earlier, mood stabilisers, including Lithium or atypical antipsychotics where necessary, could be used to treat the illness, rather than only anti-depessants We would suggest that a policy of early diagnosis and appropriate treatment of bipolar disorder is likely to be the most effective step that we can take to reduce the risk of suicide in patients with bipolar disorder (Hall et al. 2006a, Rihmer et al. 2006b, Rihmer et al. 2006c). 
Appropriate care regarding the judicious use of Venlafaxine as a first line treatment in Unipolar Depression. must be seen as secondary to this (Cipriani et al. 2007, Agius et al. 2007).

For all of these reasons, We need a single algorithm for identifying and treating affective disorders in order to optimise suicide prevention in all our depressed patients.

\section{REFERENCES}

1. Agius M, Murphy CL, Win A, Zaman R, Tavormina G: Developing primary care treatment of depression. British Journal of General Practice2007; 57:501-502.

2. Agius M, Tavormina G: Identifying and treating Bipolar Illness Early BMJ.com Feb 19th 2007.

3. Akiskal H: Bipolar Depression; the long term view. The second dual congress on Psychiatry and the Neurosciences, 1st European Congress of the International Neuropsychiatric Association; 2nd Mediterranean congress of the World Federation of Societies of Biological Psychiatry Athens 2006 Book of Abstracts $p 30$.

4. Akiskal HS: The prevalent clinical spectrum of bipolar disorders: beyond DSM-IV. J Clin Psychopharmacol 1996, 16:4S-14S.

5. Akiskal HS, Akiskal KK, Lancrenon S, Hantouche E, Fraud $J P$, Gury C, Allilaire JF: Validating the bipolar spectrum in the French National EPIDEP Study: overview of the phenomenology and relative prevalence of its clinical prototypes. Journal Affective Disorder 2006,96: 197-205.

6. Akiskal HS, Akiskal KK, Lancrenon S, Hantouche E: Validating the soft bipolar spectrum in the French National EPIDEP Study: the prominence of BP-II $1 / 2$. Journal Affective Disorder 2006, 96: 207-13.

7. Akiskal HS, Benazzi F: Optimising the detection of bipolar II disorder in outpatient private practice; toward a systematisation of clinical diagnostic wisdom. J Clin Psychiatry 2005, 66:914-921.

8. Akiskal HS, Benazzi F, Perugi G, Rihmer Z: Agitated 'unipolar' depression re-conceptualised as a depressive mixed state; implications for the antidepressant-suicide controversy. J.Affect.Disord 2005, 85;245-258.

9. Akiskal HS, Kilzieh N, Maser JD, Clayton PJ, Schettler PJ, Traci Shea M, Endicott J, Scheftner W, Hirschfeld RM, Keller MB: The distinct temperament profiles of bipolar I, bipolar II, and unipolar Patients. J.Affect. Disord 2006, 92;19-33.

10. Akiskal HS, Maser JD, Zeller PJ, Endicott J, Coryell W, Keller M, Warshaw M, Clayton P, Goodwin F: Switching from 'unipolar' to bipolar II. An 11-year prospective study of clinical and temperamental predictors in 559 patients. Arch Gen Psychiatry 1995; 52:114-123.

11. Angst J, Sellaro R: Historical perspectives and natural history of Bipolar Disorder. Soc Biol Psychiatry 2000, 48:445-457.
12. Angst: The Bipolar Spectrum. British Journal of Psychiatry 2007, 190;189-191.

13. Benazzi F, Akiskal HS: A downscaled practical measure of mood lability as a screening tool for bipolar II. J Affect Disord 2005; 84:225-232.

14. Benazzi F: Borderline personality-bipolar spectrum relationship. Prog Neuropsychopharmacol Biol Psychiatry 2006; 30:68-74.

15. Benazzi F: Does temperamental instability support a continuity between bipolarII disorder and major depressive disorder? Eur. Psychiatry 2006, 21:274-279.

16. Benazzi F: Validating Angst's 'ups \& downs' personality trait as a new marker of bipolar II disorder Eur Arch Psychiatry Clin Neurosci 2004; 254:48-54.

17. Benazzi FA: Continuity between bipolar II depression and major depressive disorder? Prog Neuropsychopharmacol Biol Psychiatry 2006; 30:1043-1050.

18. Cipriani A, Geddes J, Barbui C: Venlafaxine for major depression. BMJ 2007; 334:215.

19. Donoghue JM, Tylee A: The treatment of depression: prescribing patterns of anti-depressants in primary care in the UK. British Journal of Psychiatry 1996; 168:164-168.

20. Hall WD, Lucke J: How have the selective serotonin reuptake inhibitor antidepressants affected suicide mortality? Aust NZJ Psychiatry 2006; 40:941-950.

21. Morselli P, Elgie R: The Gamian-Europe Beam Survey; Preliminary findings of a patient questionnaire circulated to 3450 members of European Advocacy groups. Third European Stanley Foundation Conference on Bipolar Disorder September 2002.

22. NICE Bipolar Illness Guidelines, 2006.

23. NICE Depression Guidelines, 2004.

24. Paykel ES: Priest RG Recognition and management of depression in General Practice. consensus statement. BMJ 1992; 305:1198-1202.

25. Rihmer Z Akiskal H: Do antidepressants t[h]reat[en] depressives? Towards a clinically judicious formulation of the antidepressant-suicidality FDA advisory in light of declining national suicide statistics from many countries. $J$ Affect Disord 2006; 94:3-13.

26. Rihmer Z, Gonda X: Prediction and prevention of suicide in bipolar illness. The second dual congress on Psychiatry and the Neurosciences, 1st European Congress of the International Neuropsychiatric Association; 2nd Mediterranean congress of the World Federation of Societies of Biological Psychiatry Athens 2006 Book of Abstracts $p 30$.

27. Tavormina G, Agius M: A study of the incidence of Bipolar Spectrum Disorders in a private Psychiatric Practice. Psychiatria Danubina 2007; 19:370-374.

28. Tavormina G, Agius M: A study of the incidence of Bipolar Spectrum Disorders in a private Psychiatric Practice. Medicinski Arhiv 2007, 61:11.

29. Tavormina G, Agius M: The High Prevalence of the Bipolar Spectrum in Private Practice. The Journal of Bipolar Spectrum in Private Practice. The Journal of Bipolar Disorders 2007, 6:19. 